American Journal of Applied Sciences 8 (11): 1098-1100, 2011

ISSN 1546-9239

(C) 2011 Science Publications

\title{
Porosity Investigation of Kosova's Clay
}

\author{
${ }^{1}$ Makfire Sadiku, ${ }^{2}$ Naim Hasani and ${ }^{3}$ Altin Mele \\ ${ }^{1}$ Department of Chemistry, Faculty of Natural Sciences, \\ University of Prishtina, Kosova \\ ${ }^{2}$ Department of Hydromechanics, Faculty of Engineering and Architecture, \\ University of Prishtina, Kosova \\ ${ }^{3}$ Department of Chemistry, Faculty of Natural Sciences, \\ University of Tirana, Albania
}

\begin{abstract}
Problem statement: Acid activated clay minerals are used as catalysts in the desulphurization of crude oil or as catalyst carrier, drilling mud, bleaching earth. Approach: The efficiency of the acid activation can be described in two ways. As increase of the surface and as increase of the cumulative pore volume after the activation. Results: In different samples of the clay mineral the activation was done with different sulfuric acid concentrations for two and $3 \mathrm{~h}$. Afterwards the specific surface was measured by means of nitrogen adsorption. All the measured isotherms belong to the pseudo-two kind. After the activation the surface enhanced from around $100-180 \mathrm{~m}^{2} \mathrm{~g}^{-1}$. The mesopore distribution was calculated out of the hysteresis between adsorption-desorption isotherms of the nitrogen. Conclusion: It is shown that the activation increases significantly the amount of mesopores which is reflected in the cumulative volume. The macrospore volume of the clay samples were measured by means of mercury intrusion porosimetry for pore sizes up to $320 \mathrm{~nm}$. The volume of the macrospores results to an increase up to two times after the activation. The cumulative volume of all the pores is shown like a good parameter of the efficiency of the acid activation. The measurements were fulfilled in the newly equipped laboratory of the surface characterizations of the Tirana University. These analyses are of big interest for the industry in Albania and Kosove.
\end{abstract}

Key words: Acid activation, measured isotherms, mercury intrusion, equipped laboratory, porosity investigation, surface enhanced, cumulative volume, sulfuric acid

\section{INTRODUCTION}

Very high sorption properties, catalytic ion exchange of clay minerals, the possibility of finding methods to improve these properties by changing the geometrical structure, chemical nature and specific surface, the existence of deposits with significant reserves are a good starting point to deal with their study. These natural substances are used not only in catalytic processes during the production of different products but also in cleaning the pollution arising from these processes (Onal et al., 2002). The aim of this study is investigation of the change in some physicochemical characteristics, specific surface area and cumulative volume of pores of Goshica's (Kosovo) clay during activation with sulphuric acid.

\section{MATERIALS AND METHODS}

For the experiments is used the clay of Goshica Sulphuric acid p.a $\left(96 \%, \mathrm{~d}=1.83 \mathrm{~g} \mathrm{~cm}^{-3}\right)$ Gas nitrogen and liquid nitrogen Mercury.
Table 1: Suspensions composition during activation

\begin{tabular}{llll}
\hline $\begin{array}{l}\text { Acid concentration } \\
\text { versus dry mass }(\%)\end{array}$ & $\begin{array}{l}\text { Mass of } \\
\text { clay }(\mathrm{g})\end{array}$ & $\begin{array}{l}\text { Sulphuric acid volume } \\
(96 \%)\left(\mathrm{cm}^{3}\right)\end{array}$ & $\begin{array}{l}\text { Volume of } \\
\text { water }\left(\mathrm{cm}^{3}\right)\end{array}$ \\
\hline 10 & 367.1 & 12.64 & 809.76 \\
20 & 367.1 & 28.46 & 780.82 \\
30 & 367.1 & 48.79 & 743.62 \\
\hline
\end{tabular}

The ground clay was initially passed through 0.5 $\mathrm{mm}$ sieve, is washed and then follows its activation. Acid activation of clay is made with sulphuric acid (Diaz and Santos, 2001) concentration 10, 20 and 30\% versus the dry mass in different activation time (Sadiku et al., 2010). Composition of suspensions during activation is presented in Table 1 .

\section{Conditions of clay activation:}

$\begin{array}{ll}\text { Time of activation } & 2 \mathrm{~h} ; 3 \mathrm{~h} \\ \text { Temperature of activation } & 99-103^{\circ} \mathrm{C} \\ \text { Humidity of clay } & 45,52 \% \\ \text { Number of turns of stirrer } & 150 \text { rounds/min }\end{array}$

Time of activation $\quad 2 \mathrm{~h} ; 3 \mathrm{~h}$

Temperature of activation $\quad 99-103^{\circ} \mathrm{C}$

Number of turns of stirrer 150 rounds/min 
Clays have been nominated with abbreviations: G.10(2) ; G.10(3) ; G.20(2); G.20(3) ; G.30(2) ;G.30(3).

Letter $\mathrm{G}$ shows the source of clay (Goshice), the number outside parentheses concentration of sulphuric acid versus dry mass and number within brackets the time of treatment-in hours.

Adsorption and desorption of nitrogen in the temperature of liquid nitrogen is made by Volumetric Method (VM). On the basis of the amount of nitrogen adsorbed is calculated specific surface area with BET method, pore distribution and cumulative volume of pore.

The macrospore volume of the clay samples were measured by means of Mercury Intrusion Porosimetry (MIP) for pore sizes up to $320 \mathrm{~nm}$.

Mercury can penetrate inside the pores of the material by applying pressure. With the pressures applied covered macro and mesopores intervals (Abell et al., 1999). Formal link between pressure $\mathrm{p}$ and the range of a cylindrical pore is based on Washburn's equation (derived from the law of the capillaries): (Lucarelli, 2010; Tomazevic and Sheppard, 1996; Giesche, 2006; Marian et al., 2009).

\section{RESULTS AND DISCUSSION}

All earned adsorption isotherm are type II and during desorption are appeared H3 hysteresis (Fig. 1). Based on data for the amount of nitrogen adsorbed, specific surface of all samples is determined by BET method while the radius of micro pores and mesopores are calculated by Calvin equation (Gregg and Sing, 1991).

As seen in Table 2, Specific surface of natural clay is $99 \mathrm{~m}^{2} \mathrm{~g}^{-1}$ while it increased after acid treatment and reached the greatest value of samples $\mathrm{G}(20) 3$ and $\mathrm{G}(30) 2$.

The graphics for the differential pore distribution (Fig. 2), VM, shows that pore distribution of raw clay is in the region with dimensions of 1-3 nm range, (as seen from the graphs, we have dominance of pores with radius 1.2 and $2.4 \mathrm{~nm}$ ) and indicates that acid activation affects directly the change in the percentage volume of pores.

Differential pore distribution of clays treated with sulfuric acid appears as anticipated by BET determination as well with mercury intrusion porosimetry. Pores have the same size distribution, showing a slight maximum at radius $10-20 \mathrm{~nm}$ and a tendency to reach a maximum starting at $4 \mathrm{~nm}$ and continue reaching a maximum radius at about $1 \mathrm{~nm}$. This is consistent with X-ray diffraction observations of bentonite clay which give a distance of 1 nanometer of space between the layers.

Table 2: Specific surface area and cumulative pore volume (VM)

\begin{tabular}{lcl}
\hline Sample & $\begin{array}{l}\text { Specific surface } \\
\text { Area }\left(\mathrm{m}^{2} \mathrm{~g}^{-1}\right)\end{array}$ & $\begin{array}{l}\text { Cumulative pore } \\
\text { volume }\left(\mathrm{cm}^{3} \mathrm{~kg}^{-1}\right)\end{array}$ \\
\hline Non treated & 99.0 & 128.7 \\
G.10 (2) & 109.4 & 157.5 \\
G.10 (3) & 120.2 & 173.7 \\
G.20 (2) & 138.8 & 231.8 \\
G.20 (3) & 179.4 & 159.3 \\
G.30 (2) & 179.9 & 225.4 \\
G.30 (3) & 168.2 & 212.9 \\
\hline
\end{tabular}

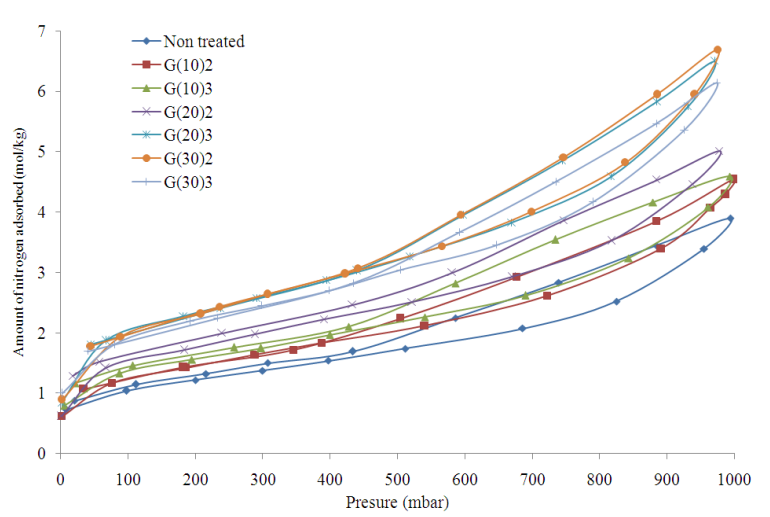

Fig. 1: Adsorption-desorbtion isotherms for all samples (VM)

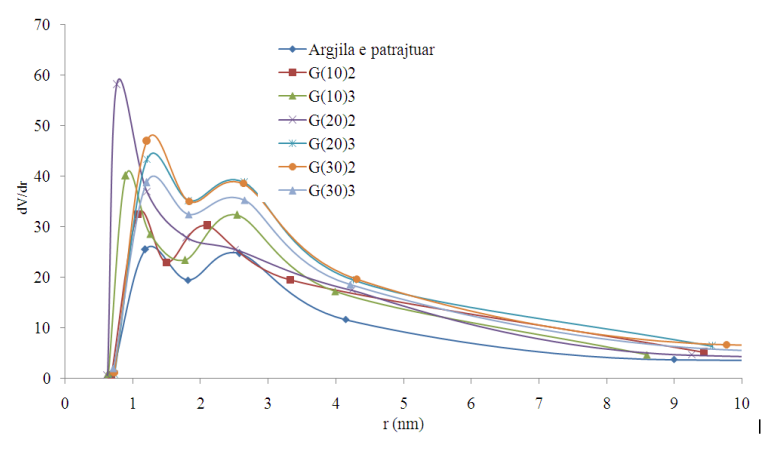

Fig. 2: Differential pore distribution for all samples (VM)

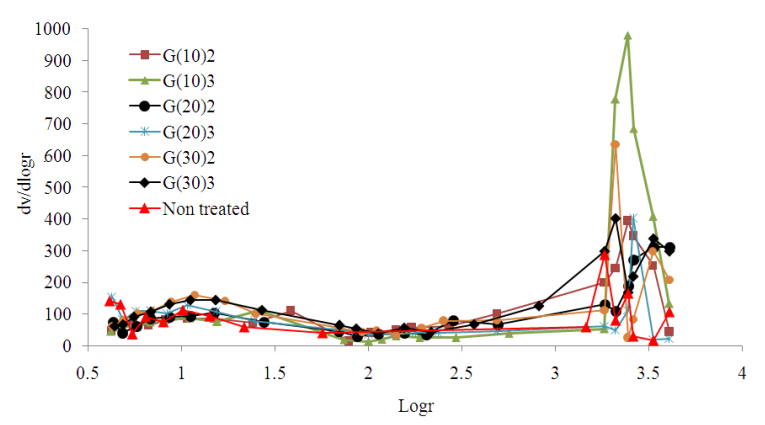


Fig. 3: Differential pore distribution for all samples (MIP)

Maximum in the differential distribution curve (MIP), (Fig. 3) $\log r=3.2-3.4(\mathrm{r}=1.5-3.5$ micrometer), does not appear due to the pore but because of interparticle spacing, indicating that clay particles have approximately the following dimensions.

\section{CONCLUSION}

Acid activation of clay increases specific surface area and cumulative volume of pores. Specific surface and general volume of pores depend on the concentration of acid used and the duration of activation. For activation time $2 \mathrm{~h}$ maximum value of specific surface area and cumulative volume of pores gives sample activated with acid $30 \%$ while the optimal values of these parameters for activation time $3 \mathrm{~h}$, achieved for the sample activated with acid $20 \%$.

The pore radii after acid treatment are almost identical with those of the untreated clay, but in higher percentage volume, so there is not increase on their range.

Results from mercury intrusion porosimetry for acidic clay provide maximum distribution of pores from 1.53.5 micrometer, indicating that clay particles have approximately the following proportions

\section{REFRENCES}

Abell, A.B., K.L. Willis and D.A. Lange, 1999. Mercury intrusion porosimetry and image analysis of cement-based materials. J. Colloid Interface Sci., 211: 39-44. DOI: 10.1006/JCIS.1998.5986
Diaz, F.R.V. and P.D.S. Santos, 2001. Studies on the acid activation of brazilian smectitic clays. Quim. Nova.

Giesche, H., 2006. Mercury porosimetry: A General (Practical) Overview. Part. Part. Syst. Charact., 23: 9-19. DOI: $10.1002 /$ ppsc. 200601009

Gregg, S.J. and K.S.W. Sing, 1991. Adsorption, Surface Area and Porosity. 2nd Edn., Academic Press, London, ISBN-10: 0123009561, pp: 303.

Lucarelli, L., 2010. The use of mercury intrusion porosimetry for the determination of particle size distribution on nano-particles carbon black. Microstructure Product Line, Thermo Electron Corporation, Milan-Italy.

Marian, M., L.M. Cozmuta, C. Varga, A.M. Cozmuta and E. Nour, 2009. Vegetation dynamics depending on ecological particularities of bozanta mare (Maramures county-Romania) tailing pound. Case study. Am. J. Environ. Sci.., 5: 116-123. DOI: 10.3844/ajessp.2009.116.123

Onal, M., Y. Sarikaya, T. Alemdaroglu and I. Bozdogan, 2002. The effect of acid activation on some physicochemical properties of a bentonite. Turkish J. Chem., 26: 409-416.

Sadiku, M., N. Hasani and A. Mele, 2010. The effect of acid activation on some physicochemical properties of Goshica's clay, J. Int. Environ. Appli. Sci., 5: 594-599.

Tomazevic, M. and P. Sheppard, 1996. Slovenian National Building and Civil Engineering Institute. 1st Edn., Zavod za gradbenistvo, Ljubljana,ISBN9619036603, pp: 46. 